\title{
Plasma cutting in atmosphere and under water
}

\author{
W. Bach and A. Gruchow \\ Institut für Werkstoffkunde (IW), Universität Hannover, Germany
}

\begin{abstract}
This paper shows an overview of all kinds of plasma arc cutting techniques which are actually applied to practical purposes. In respect to cutting in atmosphere, noxius emissions of noise, fumes, aerosols and harming gases. In respect to cutting under water, a number of special constructions for the decommissioning of nuclear facilities and for offshore applications are described, as the plasma saw, the staff torch, the modular torch and the low voltage short-circuiting arc ignition for greater depths of water. Also the influence of the surrounding water on the appearance of the cutting kerf and metallurgical changes in the heat-affected-zone are shown.
\end{abstract}

\section{INTRODUCTION}

Thermal plasma is a highly heated gas or gaseous mixture which is conductive and consists mostly of free electrons and ions. The arc strikes between the plasma arc cutting torch's electrode, which is connected as the cathode, and the anode.

In general, it is possible to cut by means of a non-transferred arc (so-called indirect mode), if the plasma torch's nozzle forms the anode. Thus, also nonconductive materials can be cut. Since, however, only less cutting current may be used, owing to the nozzle's intense exposure to heat, and since there is also only a low level of energy led into the workpiece, this method has not gained practical importance.

Nearly all commercial plasma torches avail themselves of the nontransferred or indirect principle, under which the workpiece forms the anode. A small pilot arc must be initiated by means of a highfrequency high voltage spark between the electrode and the nozzle to start the main plasma arc. The nozzle is connected as an auxiliary anode during this procedure. The pilot arc is blown out of the nozzle's orifice by the increasing pressure of the plasma gas inside the cathode space and flashes over onto the workpiece.

\section{PLASMA ARC CUTTING TECHNIQUES}

The following plasma arc cutting techniques are used with particular torch constructions and plasma gases [ref. 1, 2, 3]:

\section{$\mathrm{Ar} / \mathrm{N}_{2} / \mathrm{H}_{2}$ technique}

For a long time, a mixture of argon, nitrogen and hydrogen was most frequently used as plasma gas, both for cutting in atmosphere and under water. The wide range of applications which includes nearly all common metal materials over a wide range of sheet thicknesses is an advantage. The fractions of the single gases differ according to the material and the plate thickness. Occasionally, even gaseous mixtures which consist merely of two components are used. The torches are usually equipped with an indirectly cooled tungsten electrode and a copper nozzle. 


\section{Dual-flow technique}

The dual-flow technique was derived from the $\mathrm{Ar} / \mathrm{N}_{2} / \mathrm{H}_{2}$ technique by covering the plasma arc in underwater service with an additional secondary gas (either $\mathrm{CO}_{2}$ or compressed air). Thus the cooling effect of the surrounding water, which lessens the power efficiency, is reduced and the water is kept away from the front of kerf.

\section{Water-injection-plasma-cutting (WIPC) technique}

In recent times the above mentioned variants have been more and more replaced by the WIPC technique. In this case the plasma gas (nitogen or oxygen) swirls around the directly cooled flat electrode. The complete nozzle consists of two parts: a copper nozzle and a ceramic nozzle below. Between these both a small jet of water ( $<21 / \mathrm{min}$ ) is sprinkled onto the plasma arc. These arrangements lead to a better constriction of the arc. An asymmetrical shape of the kerf with one vertical edge of cut occurs owing to the swirling action of the plasma gas and therefor the quality of cut is higher compared with other plasma cutting techniques. The WIPC technique is used under water or in atmosphere with both using or not using a water-muffler.

\section{Compressed air technique}

The plasma arc cutting with compressed air is mainly used to cut mild steel in atmosphere. Special, directly cooled copper electrodes with an insert of hafnium must be used. Mostly the mobile equipment for manual use is designed only for low-duty cutting of thin sheets.

\section{PLASMA ARC CUTTING IN ATMOSPHERE}

When plasma arc cutting was first developed, it was only used for cutting in atmosphere, but it is now more and more applied in shallow water at depths up to $100 \mathrm{~mm}$. Although cutting under water involves a more difficult processing control, leads to restrictions in handling, and lowers the cutting speed ( $f i g$. 1), cutting in atmosphere is being more and more replaced as a consequence of the extremely high noxius load, both for the environment and for the workplace, by emissions of noise, aerosols - involving the risk of cancer and fibroids (when cutting stainless steel), hazardous gases (NOx and ozone), and uvradiation.

Cutting in atmosphere causes a noise level of between 100 and 120 $\mathrm{dB}(\mathrm{A})$. The usage of a water-muffler with a higher throughput (80 $1 / \mathrm{min}$ ) provides for a coaxial water curtain around the arc and reduces the noise level to $20 \mathrm{~dB}(\mathrm{~A})$, if the workpiece is lying on the water surface. Also by this way the quantity of aerosol emission can be reduced to between $1 / 4$ and $1 / 10$ of the usual value, depending on the specific chemical composition. If the cutting process is displaced to water depths of 50 to $100 \mathrm{~mm}$, levels of only 75 to $85 \mathrm{~dB}(\mathrm{~A})$ occur, whereas the noise reduction is proportional to the water depth [ref. 3].

At the IW the aerosol emission while cutting mild steel and stainless steel under water and under air influence were compared (fig. 2). Both materials show similar changes in the quantities of aerosol emission which increases proportionally according to the plate thickness. But cutting under water reduces these values to between $1 / 50$ and $1 / 1000$ compared with cutting in atmosphere [ref. 4].

However, the formation of the noxius gases No and ozone by uvradiation is only a little influenced. Therefore, fume exhausters are necessary which must have a high throughput over a large area when 


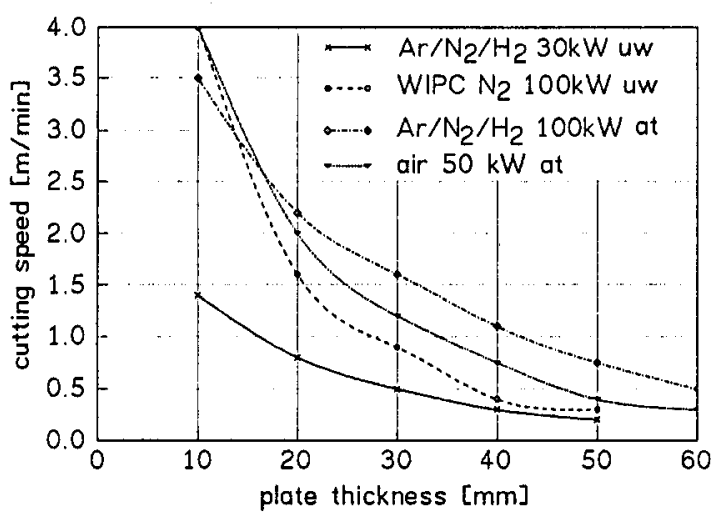

Fig. 1. Cutting speed with different techniques

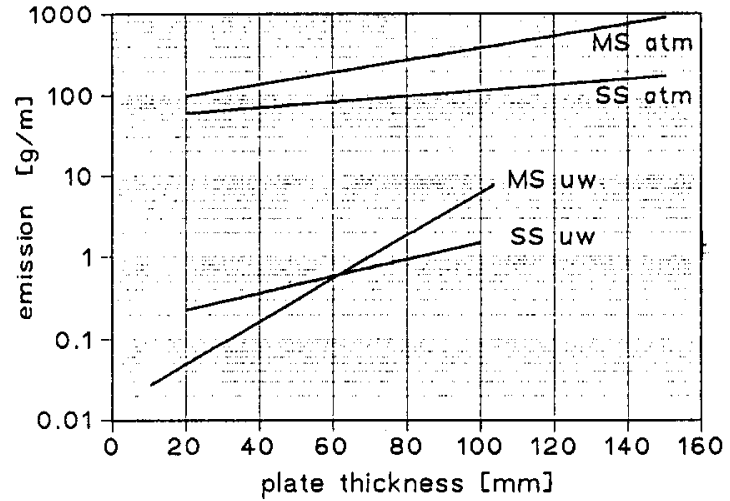

Fig. 2. Aerosol emission, MS - mild steel, SS - stainless steel

cutting in atmospheric conditions. For underwater cutting these exhausters merely need to be little hoods around the torch, constructed for small throughputs.

\section{PLASMA ARC CUTTING UNDER WATER}

\section{Sheet fabricating and shipbuilding industry}

Because of the above mentioned reasons, plasma arc cutting under water is more and more frequently used. Cutting under a layer of water of up to $100 \mathrm{~mm}$ is used in the sheet fabricating industry and specially in the shipbuilding industry. In the latter, the increasing use of high quality stainless steel and aluminum causes oxyacetylene flame cutting to be more and more replaced. Large gantry cutting machines with 1 to 4 single torches, applying the dual-flow or mostly the WIPC technique are mainly used for the higher performance range of 50 to $100 \mathrm{~kW}$ for precise shape cutting or simple weld preparation.

Modular cutting torches are under development, which provide for quick, remote changing of wearing parts, as well as, for the application of different plasma arc cutting techniques in one machine. Thus, the highly wear-exposed nozzles and electrodes can be replaced while the machines discontinue working only for short periods and the torch can be adapted to each individual cutting job.

Today it becomes more and more necessary to cut more complicated grooves for double-V, $Y$ and double-Y welds, which are common for sheets of above $20 \mathrm{~mm}$ thickness, in several consecutive processing steps. To produce these profiles in one single operation, special flat-ended torches have been developed at the IW. Owing to the narrow overall width of $22 \mathrm{~mm}$ or less, three torches are assembled close to each other in one line - as customary for oxyacetylene torches - on a rotatable carrier.

\section{Decommissioning of nuclear facilities}

Underwater Plasma cutting has much to recommend it for the cutting of stainless steel in the course of decommissioning nuclear facilities, because the torches operate without causing restoring forces and no secondary waste is produced. The cutting equipment for this application needs to work perfectly up to water depths of $20 \mathrm{~m}$. At the IW, a large number of special torches have been developed and qualified in order to be able to do the far range of highly complex cutting jobs, which occur. 
Modular torch systems are inevitable for the remote controlled replacement of wear parts by manipulators. This also provides the obligation to switch between straight and cranked aggregates. This equipment must be as small as any possible, owing to their handling in confined, complex structures (fig. 3 ).

Should this be impossible or the tube's diameter be to small, a staff torch can be let into the tube to cut it from inside. The plasma arc is ejected through a beveled plasma nozzle orifice, which is arranged eccentric to the torch's axis, and the tube is cut while the torch makes one complete turn about its axis (fig. 4).

The maximum plate thickness to which underwater plasma cutting of stainless steel applies is $100 \mathrm{~mm}$. Therefore, the plasma saw has been developed for components of greater thicknesses. It works under the principle of an immersing torch. Twelve plasma arc cutting torches are arranged around a disk. These torches are supplied through a feeder, positioned on the saw's axle (fig. 5). Each single torch is

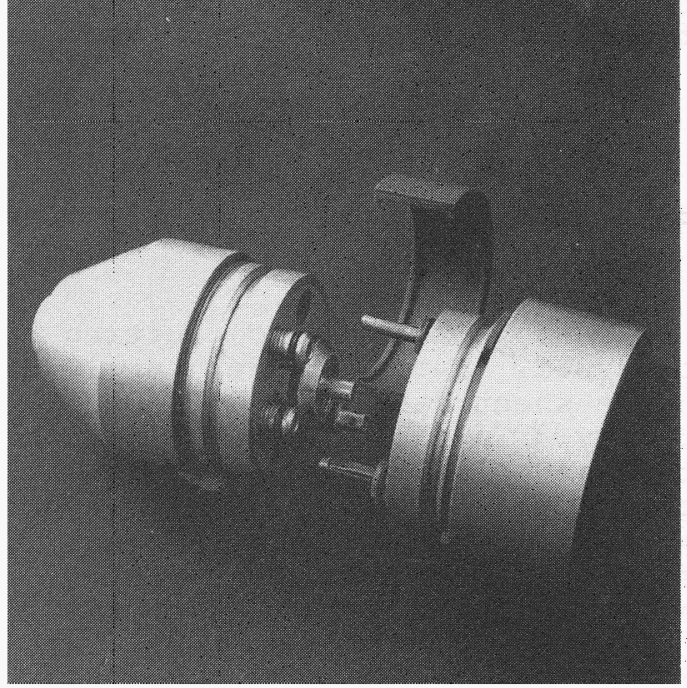

Fig. 3. Modular torch

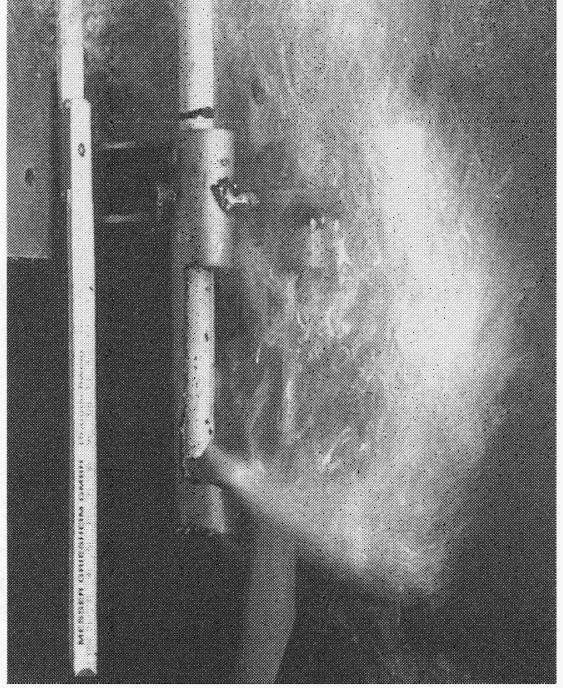

Fig. 4. Staff torch

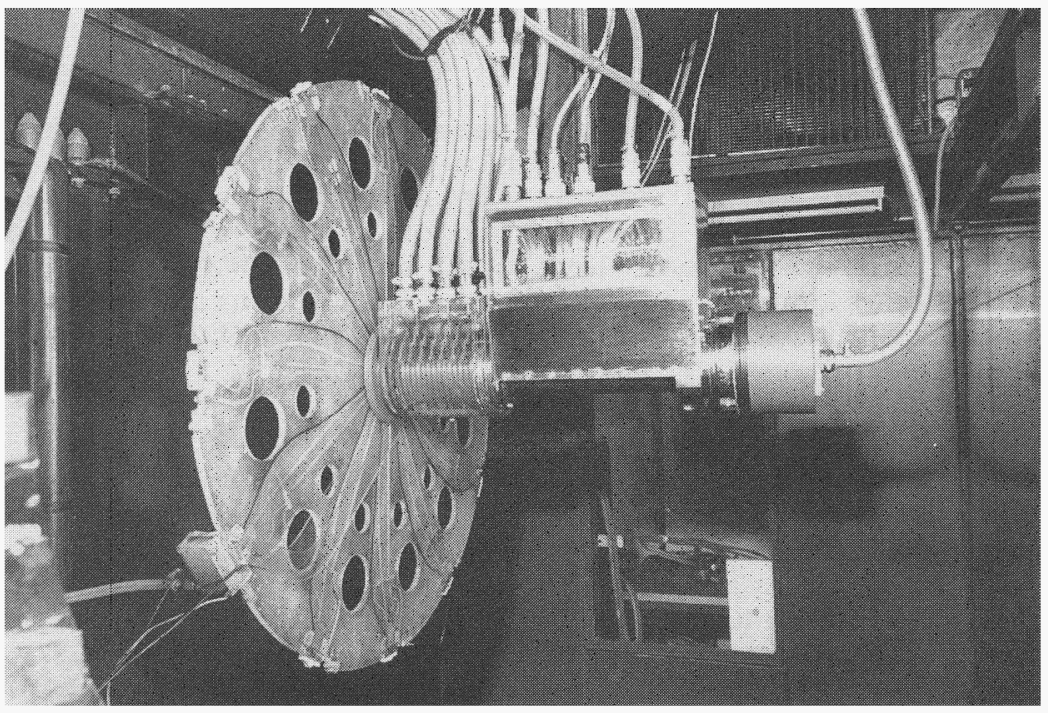

Fig. 5. Plasma saw 
ignited, when immersing into the workpiece, melts the material, while going through the kerf, and ceases burning, when leaving the workpiece. Using this technique, the maximum wall thickness of a workpiece to be cut merely depends on the diameter of the disk. Such a plasma saw has been demonstrated cutting $300 \mathrm{~mm}$ stainless steel, as well as, tubes of greater diameter and heat exchangers.

\section{Offshore industry}

The offshore industry can use plasma arc cutting to partly dismount, completely break down, or repair existing offshore installations, e.g. platforms or pipelines. In the course of wet weld preparation, it is necessary to obtain a high quality of cut in order to minimize the considerable expenditure of subsequent machining. Besides the usual vertical cuts, bevel cuts with an inclination angle of $30^{\circ}$ are particularly appropriate for this purpose as a preparation for the typical v-groove welds.

To increase the quality of cut even at greater depths of water, conventional plasma arc cutting torches are modified. The use of ceramic swirl rings between electrode and nozzle, for example, improves the electrode's centeric adjustment to the nozzle's orifice. These ceramic rings can provide a swirling flow of the plasma gas around the electrode, in stead of streaming parallel to the electrode's axis. This causes a better constriction of the arc and thus leads to an higher temperature and an increased stability of the arc. The practical advantages of these are an improved ignition at greater depths, as well as, considerably reduced amount of dross at the bottom edge of cut and roughness of the cut surface (fig. 6).

If higher ambient pressure, the ignition of the plasma arc through high voltage causes problems, as the required breakdown voltage increases superproportional to the ambient pressure. Therefore, on the one hand, more powerful igniters and, on the other hand, a shortcircuiting arc ignition, which is independent from the surrounding pressure, are under development. Therefor, special torches are required, with electrodes that can be axially moved by pneumatics to make contact with the nozzle [ref. 5].

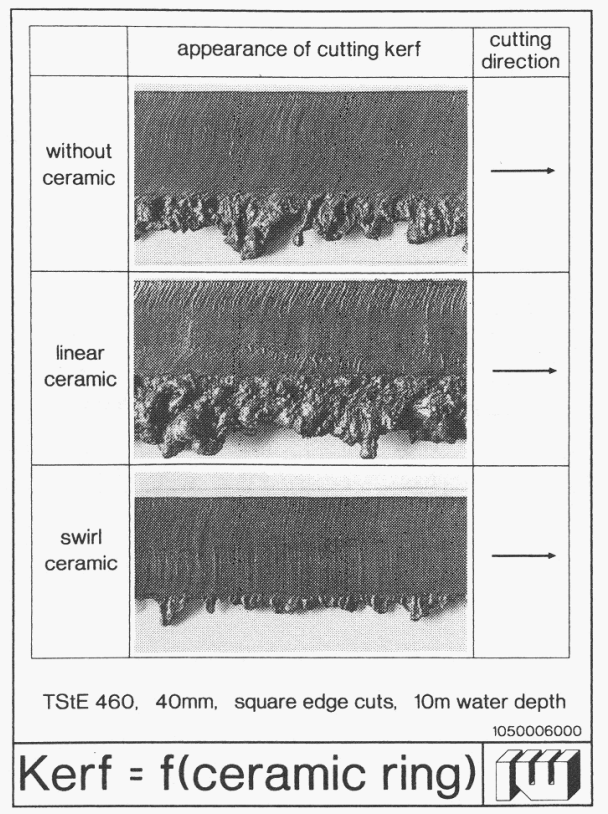

Fig. 6. Effect of different swirl ceramic rings

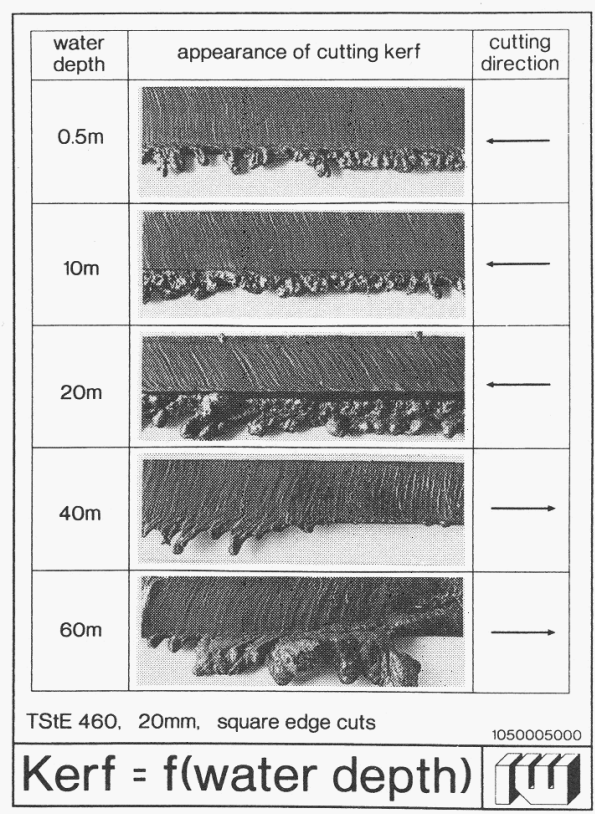

Fig. 7. Plasma cuts at different depths of water 
cutting tests have been performed at different simulated depths of water down to $60 \mathrm{~m}$ with fine grained steel stE 460 of 20 and $40 \mathrm{~mm}$ thickness (fig. 7). The amount of dross and the hollowness of the cut surface increase considerably with the depth of water. Down to $20 \mathrm{~m}$, it is possible to produce vertical cuts, as well as, $30^{\circ}$-bevel cuts which can be classified as quality zone 1 and 2, Grade I (according to the German Industrial standard 2310, part 4), owing to optimized cutting parameters. At $20 \mathrm{~m}$ depth, the cutting speed is reduced to the half in spite of twice electrical power in comparison to shallow water. The roughness $R_{z}$ doesn't differ evidently about 20 to $50 \mu \mathrm{m}$ [ref. 6].

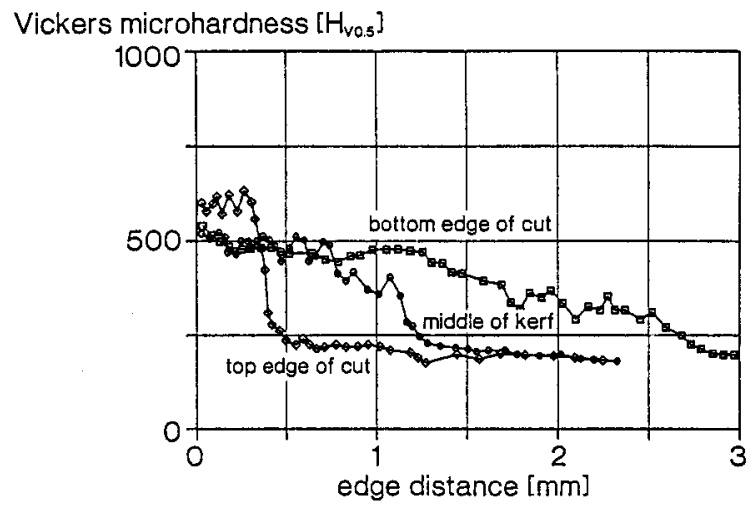

material: TStE 460, thickness: $20 \mathrm{~mm}$, water depth: $0.5 \mathrm{~m}$

Fig. 8. Hardness traverse

Investigations of structure micrographs showed that the heat-affected-zone (HAZ) grows proportional to ambient pressure because of less cutting speed. Measurements of the hardness traverse of the HAZ at different distances from the top edge of cut differ extremely. The maximum values immediately at the cut surface are similar at 500 to 600 Vickers microhardness HVO.5. However, the HAZ's width varies from $0.4 \mathrm{~mm}$ at the top edge of cut and $1.2 \mathrm{~mm}$ in the middle to $2.7 \mathrm{~mm}$ at the bottom edge of cut (fig. 8) [ref. 6].

\section{REFERENCES}

1. F.-W. Bach, 'Underwater Cutting Techniques Develpments', Proc. Decommissioning of Nuclear Inst., Brussels, (Oct. 24-27.1989)

2. 'Recommended Practices for Plasma Arc Cutting', AWS C5.2-73, (1981)

3. M. Mawson, Metal Constr. No.8, 444-447, (1983)

4. H. Steiner, F.-W. Bach, D. Windelberg, B. Georgi, 'Aerosol Generation ...', European Aerosol Conf, Lund Sweden, (Aug. 30. 1988)

5. H. Haferkamp, F.-W. Bach, K. Koch, DVS-Berichte 89, 102-110, (1989)

6. H. Haferkamp, F.-W. Bach, A. Gruchow, 3. Intern. Symp. on Underwater Technology, Geesthacht, 20/01-20/08, (Apr. 9-10.1991) 